\title{
Erratum to: Does South Korea have hidden female smokers: discrepancies in smoking rates between self-reports and urinary cotinine level
}

Myung Bae Park ${ }^{1,2,3,4}$, Chun-Bae Kim², ${ }^{2,3^{*}}$ Eun Woo Nam ${ }^{1,3,4}$ and Kyeong Soo Hong ${ }^{5}$

Following the publication of this article [1] it was noticed by the author that Fig. 1 contained additional information which should not have been included in the figure. The tables in the figure which were used to create the graph should have been cut from the figure before publication. The correct figure has been included below.

\begin{abstract}
Author details
'Department of Health Administration, Yonsei University, Gangwon-Do, Republic of Korea. ${ }^{2}$ Department of Preventive Medicine, Yonsei University Wonju College of Medicine, 162 Ilsan-Dong, Wonju-City, Gangwon-Do 220-701, Republic of Korea. ${ }^{3}$ Yonsei University Institute for Poverty Alleviation and International Development, Gangwon-Do, Republic of Korea. ${ }^{4}$ Healthy City Research Center, Institute of Health and Welfare, Yonsei University, Gangwon-Do, Republic of Korea. ${ }^{5}$ Korea Health Promotion Foundation, Seoul, Republic of Korea.
\end{abstract}

Received: 24 December 2015 Accepted: 24 December 2015

Published online: 04 January 2016

\section{References}

1. Park MB et al. Does South Korea have hidden female smokers: discrepancies in smoking rates between self-reports and urinary cotinine level. BMC Womens Health. 2014;14:156.
*Correspondence: kimcb@yonsei.ac.kr

${ }^{2}$ Department of Preventive Medicine, Yonsei University Wonju College of Medicine, 162 Ilsan-Dong, Wonju-City, Gangwon-Do 220-701, Republic of Korea

${ }^{3}$ Yonsei University Institute for Poverty Alleviation and International Development, Gangwon-Do, Republic of Korea
Submit your next manuscript to BioMed Central and we will help you at every step:

- We accept pre-submission inquiries

- Our selector tool helps you to find the most relevant journal

- We provide round the clock customer support

- Convenient online submission

- Thorough peer review

- Inclusion in PubMed and all major indexing services

- Maximum visibility for your research

Submit your manuscript at

www.biomedcentral.com/submit

\section{Biomed Central}




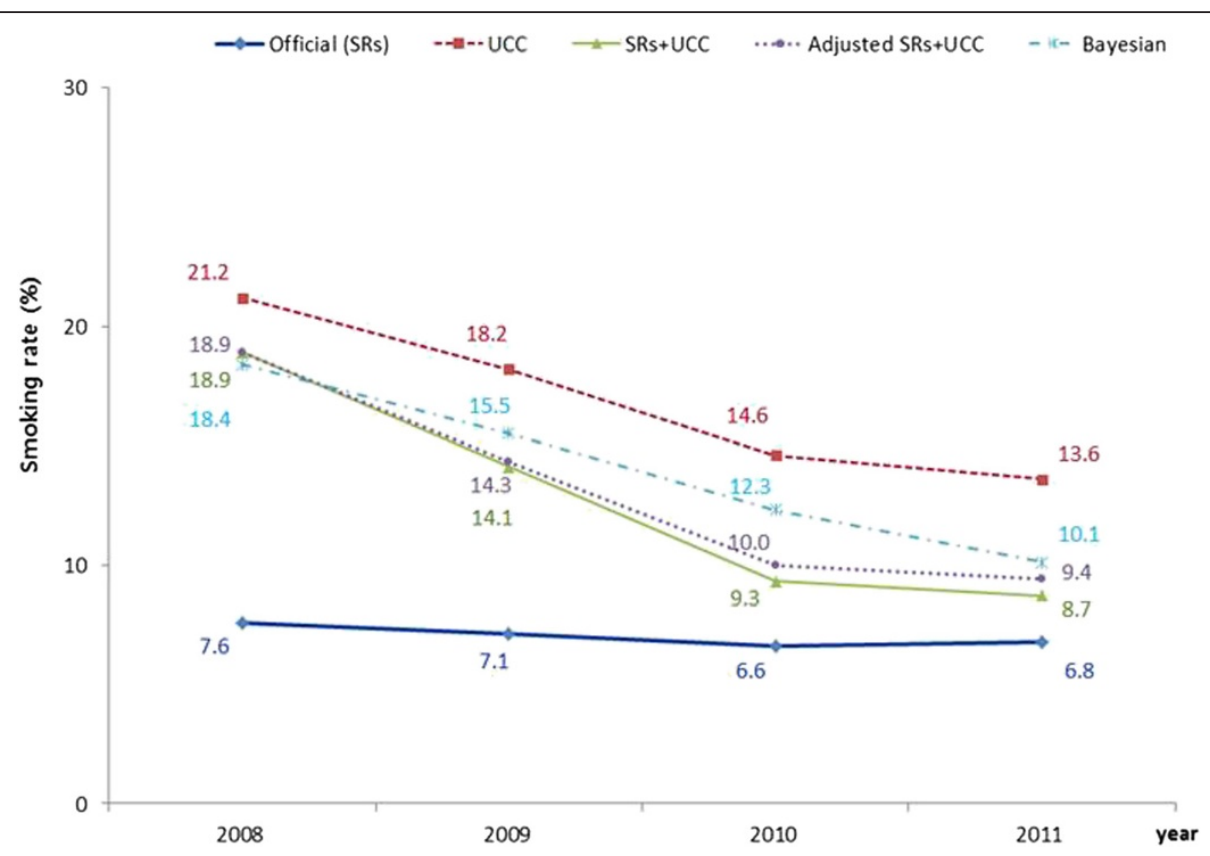

Fig. 1 Female smoking rate by year. SR self-reported surveys. UCC urinary cotinine concentration 